\title{
Mobile Positioning System using Signal Strength Measurement for WCDMA System
}

\author{
Farhad . E .Mahmood \\ College of Engineering \\ University of Mosul \\ Mosul, Iraq \\ frhad_100@yahoo.com
}

\author{
Ahmad M. A. Salama \\ College of Electronics Engineering \\ University of Mosul \\ Mosul, Iraq \\ ahmad2salama@yahoo.com
}

\begin{abstract}
The precise position of the mobile station is critical for the ever increasing number of applications based on location . In this paper a new approach for mobile positioning in WCDMA (Wideband Code Division Multiple Access ) cellular network is proposed . Radio Received Signal Strength Indication (RSSI) can be measured from a number of nearby base stations. Three proposed approaches (3-BS's , 5-BS's and 7-BS's) are simulated using three propagation models and the $\mathbf{r m s}_{\text {error }}$ is calculated for each model. As a simulation study case, the University of Mosul area is choosed to find the position of a mobile user in the university campus .
\end{abstract}

Keywords: positioning systems, WCDMA ,RSSI, propagation models.

نظام تحديد موقع الهاتف النقال باستخدام قياس شدة الإثارة في نظام(WCDMA)

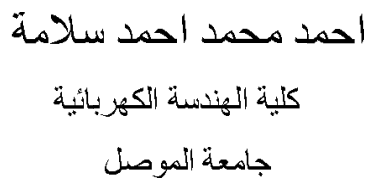

$$
\begin{aligned}
& \text { فر هاد عز الدين محمود } \\
& \text { كلية هندسة الاكترونيات } \\
& \text { جامعة أموصول }
\end{aligned}
$$

\section{الخلاصة}

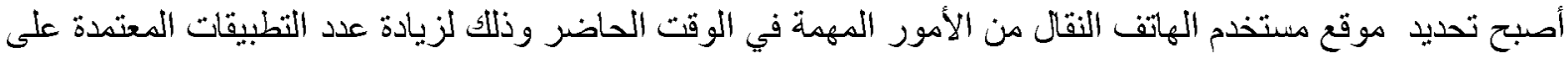

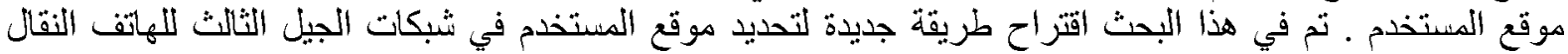

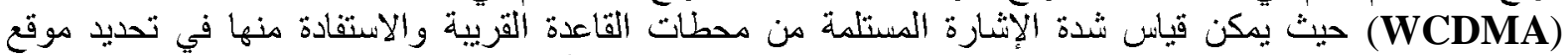

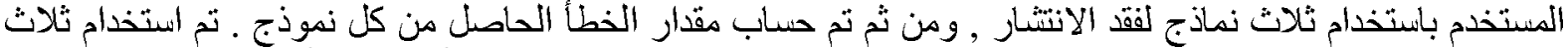

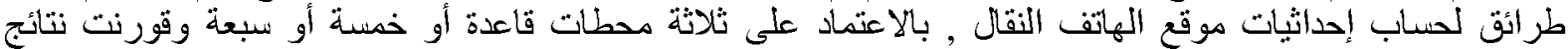
الطر ائق الثلاث بالاعتماد على نسبة الخطا لإيجاد الطريقة الأهثل ـ طبق نظام المحاكاة في جامعة الموصل لتحديد موقع مستخدم موجود داخل الحرم الجامعي . 


\section{Introduction}

Mobile positioning in cellular mobile networks provide several services such as locating stolen / lost mobile, emergency calls network, self optimizations different billing tariffs depending on where the call is originated and other applications.

Position finding in 2nd generation mobile system (GSM, CDMA ) are depends on Time Of Arrival (TOA) from Base Station (BS) to Mobile Station (MS) to calculate the distance between them. BS in these systems is synchronized with MS, but there is no synchronization in WCDMA system (a synchronized ) [1].

The main disadvantage of GPS/AGPS( Assisted GPS) and (TOA) systems is that they assume Line-of-Sight (LOS) propagation between the transmitter and the receiver. In general this assumption is not valid in city centers where LOS is often blocked by buildings and other obstacles. The accuracy of these systems is significantly degraded by the multi-path propagation caused by signals bouncing off buildings or other elevated topological features. In mountainous areas characterized by narrow valleys and few base stations, both AGPS and TOA performance may degrade severely. Consequently companies have started to look into other methods of providing location capabilities in multi-path areas and particularly in socalled dense urban environments [2].

In this paper the Received Signal Strength Indication (RSSI) is used to find distance between base station and mobile using outdoor propagation models, where there is no need for TOA (a synchronized system). Three models are used to find the distance.

\section{Working Area}

In this paper the simulation is applied to Mosul university for an area of $(4 \mathrm{~km} \times 2.5 \mathrm{~km})$ at Mosul city (Iraq) obtained from Google Earth software as shown in Fig. (1). The NPSW (network planning strategies for wideband CDMA ) program is used in simulation with a static simulation program based on MATLAB software and adapted by IEEE [3]. The program requires the following data [4]:

-The topographical map of the area.

-The mobile stations map and base stations map.

These data are added as layers.

The process is to input the digital map to the NPSW program which contains three parameters length, width and colors:

- The first step is to consider just the length and width for the intended area map as a terrain layer.

- The second step is to add the water layer represented by the blue color.

- The third step is to add the streets layer represented by black color.

The resolution of the blue color and black color should be high in order to avoid putting the base station towers in the middle of streets or water areas.

- The forth step is to add the base stations layer to show the BSs locations and the number of antenna sectors .

- The fifth step is adding the MSs Layer to show users distribution and data rate which represent different bit rate.

This picture entered to NPSW for first layer as the topographical map of the area (digital map). The second layer in NPSW is BS layer, with omni directional antenna (25m height) . 


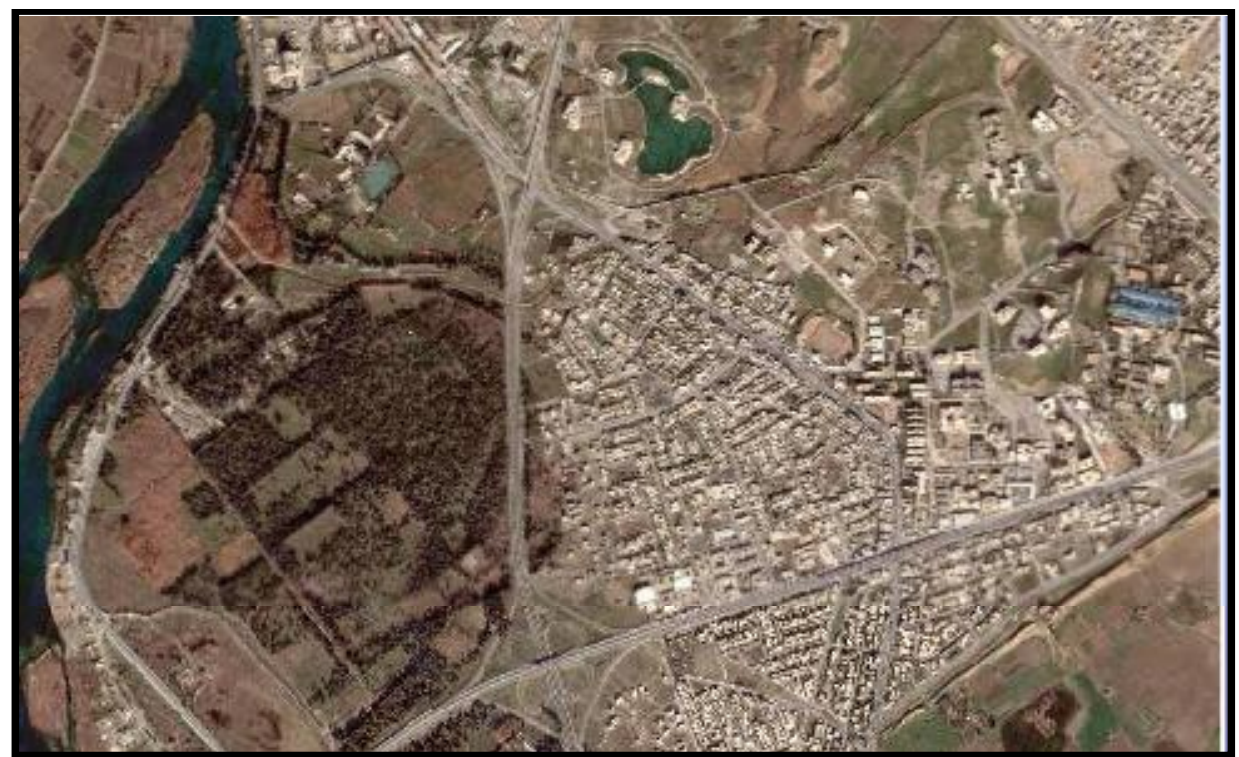

Fig. (1): Working Area of $\left(4 \times 2.5 \mathrm{~km}^{2}\right)$ at Mosul city including University of Mosul campus .

\section{Mathematical Approach}

The MS should lie in the coverage area of at least three BSs in order to determine it's location as shown in Fig. (2) where the coverage of the BSs are represented by a circles centered at the BS. The distance between the MS and the three BSs will be used to solve the following three equations [5]:

$$
\left.\begin{array}{l}
\left(\mathrm{x}-\mathrm{x}_{1}\right)^{2}+\left(\mathrm{y}-\mathrm{y}_{1}\right)^{2}=\mathrm{d}_{1}{ }^{2} \\
\left(\mathrm{x}-\mathrm{x}_{2}\right)^{2}+\left(\mathrm{y}-\mathrm{y}_{2}\right)^{2}=\mathrm{d}_{2}{ }^{2} \\
\left(\mathrm{x}-\mathrm{x}_{3}\right)^{2}+\left(\mathrm{y}-\mathrm{y}_{3}\right)^{2}=\mathrm{d}_{3}{ }^{2}
\end{array}\right\}
$$

where $(\mathrm{x}, \mathrm{y})$ is the mobile's location; $\left(\mathrm{x}_{1}, \mathrm{y}_{1}\right)$, $\left(\mathrm{x}_{2}, \mathrm{y}_{2}\right)$ and $\left(\mathrm{x}_{3}, \mathrm{y}_{3}\right)$ are the coordinates of $\mathrm{BS}{ }_{1}$, $\mathrm{BS}_{2}$ and $\mathrm{BS}{ }_{3}$ respectively; $\mathrm{d}_{1}, \mathrm{~d}_{2}$ and $\mathrm{d}_{3}$ are the distances from $\mathrm{BS}_{1}, \mathrm{BS}_{2}$ and $\mathrm{BS}_{3}$ to the mobile station MS respectively; as shown in Fig. (2), where intersection of three circles represent the location of the MS..

\section{Propagation Models Simulation}

To find the distance $\mathrm{d}$ between the MS and BSs, a suitable propagation model should be used. Three propagation models are used in simulation to find $\mathrm{d}$ based on RSSI using MATLAB software 7.4 version. Once the distances $\left(\mathrm{d}_{1}, \mathrm{~d}_{2}\right.$ and $\left.\mathrm{d}_{3}\right)$ are obtained, the location ( $\mathrm{x}, \mathrm{y}$ ) of the MS can be found using equation (1). The propagation models used in simulation are:

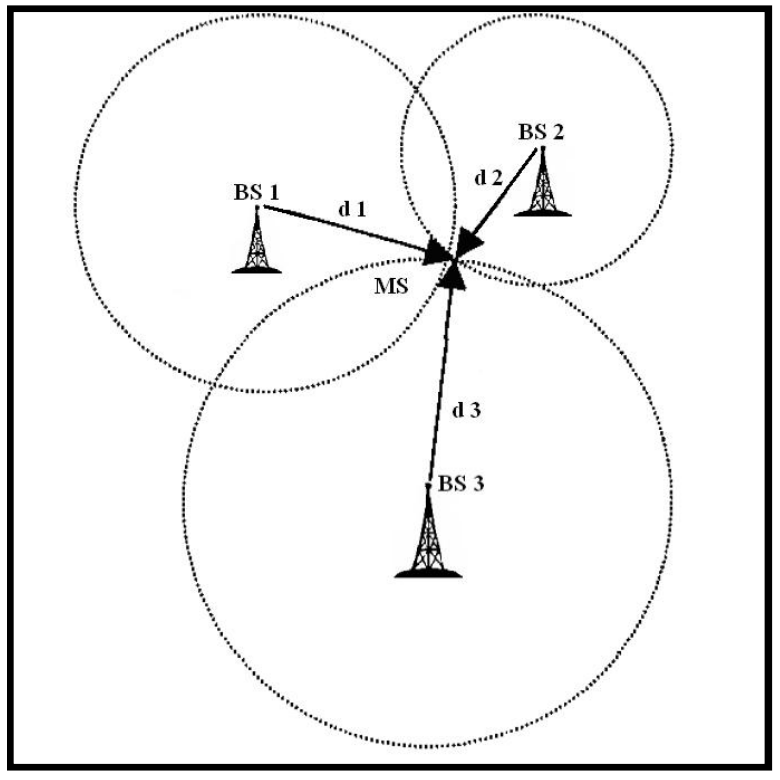

Fig. (2): Mobile positioning using three base stations 
Okumura-Hata model (OH) [3] :

path_loss $=158.3-13.82 \log \left(H_{B T}\right)+\left(44.9-6.55 \log \left(H_{B T}\right)\right) \log (d)$

UMTS 30.03 model [6] :

path_loss $=40\left(1-4 * 10^{-3} \Delta H b\right) \log (d)-18 \log (\Delta H b)+149.3$

Long distance model [7] :

$$
\text { path_loss }=136.86+40 \log (d)
$$

Where $\left(H_{B T}\right)$ is BS antenna height, $\triangle H b$ is difference between BS antenna height and MS height ( $1.5 \mathrm{~m})$ and (d) is the BS-MS distance .

Three approaches are used in simulation, the first one assumes three base stations (3-BS's) existed in the working area; the second approach uses a five base stations (5-BS's) and the last one uses a seven base stations (7-BS's) distributed around the working area (University of Mosul). Just three base stations are needed in the simulation to find the location of the MS, so the algorithm will choose the highest three signals (i.e nearest BSs) in 5-BS's and 7-BS's approaches (these signals are control channels CPICH (Common Pilot Channel) [3] which are set to $30 \mathrm{dBm}$ for all BSs in network and are unchangeable). Fig. (3) shows the working area and the locations of the base stations and table.(1) gives BSs parameters .

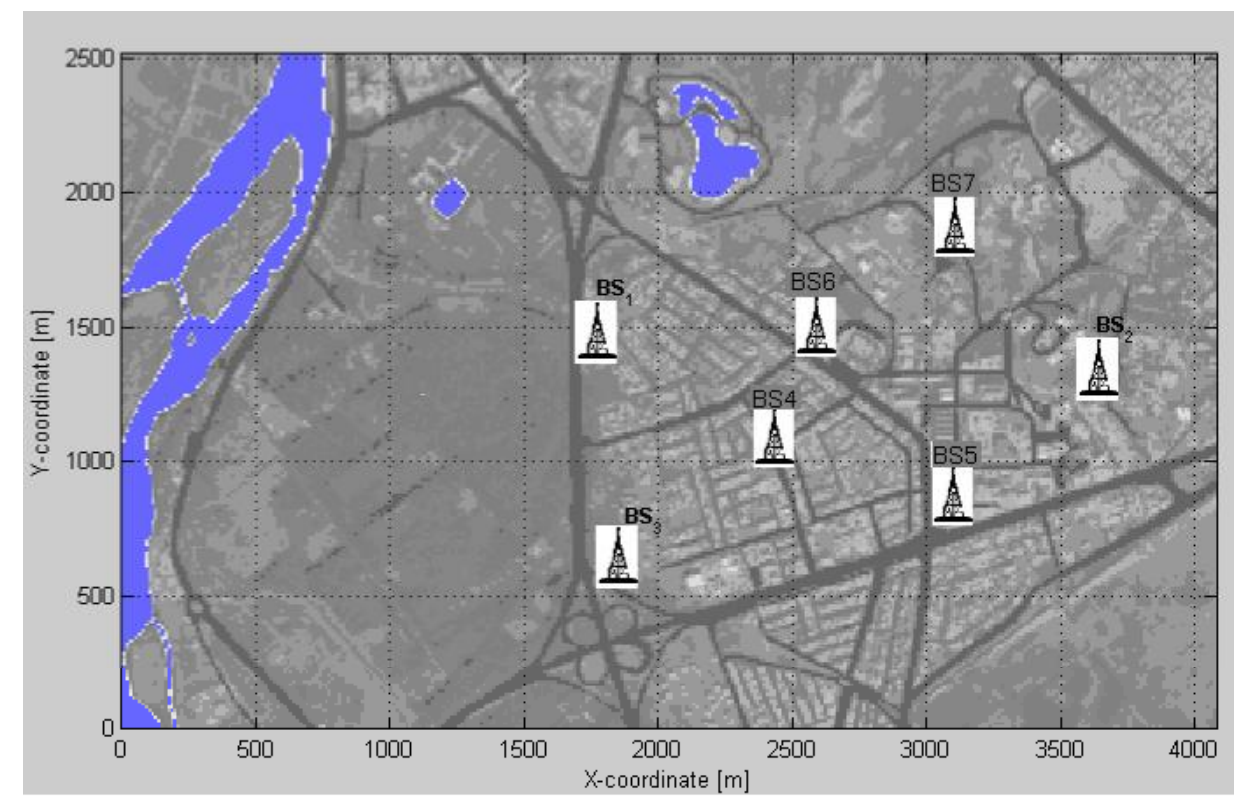

Fig.(3): Working area and the locations of the base stations.

Table 1: Base Stations parameters.

\begin{tabular}{||c||c||c||c||c||c||}
\hline \hline & X pos & Y pos & $\begin{array}{c}\text { Ground } \\
\text { height }\end{array}$ & $\begin{array}{c}\text { Antenna } \\
\text { height }\end{array}$ & $\begin{array}{c}\text { Power } \\
\text { (dBm) }\end{array}$ \\
\hline BS1 & 1758 & 1428 & 227 & 25 & 30 \\
\hline BS2 & 3622 & 1290 & 230 & 25 & 30 \\
\hline \hline BS3 & 1863 & 577 & 226 & 25 & 30 \\
\hline \hline BS4 & 2444 & 1000 & 224 & 25 & 30 \\
\hline BS5 & 3040 & 760 & 226 & 25 & 30 \\
\hline \hline BS6 & 2550 & 1500 & 227 & 25 & 30 \\
\hline BS7 & 3200 & 1660 & 233 & 25 & 30 \\
\hline
\end{tabular}

The simulation flowchart is shown in Fig. (4). When a user has to be located, the MS number corresponding to that user is retrieved from the data base and the central unit send a message 
to all MSs in the coverage area. Just one is intended, which will reply and respond to the location request service, then MS will determine the location after measuring the received signal from nearest BSs, The MS will choose the highest three signals, if 5-BS's and 7-BS's approaches is used, and then calculate the distance from MS to each one of the BSs. After calculation, the MS will send the location to BS then to the central unit to find location, this procedure is presented in Fig. (4). The system will be able to show the route taken by the object or person by plotting the last detected positions and connecting them.

The accuracy of the object positioning is specified as follows [5]:

$$
r m s_{\text {error }}=\sqrt{(X-x)^{2}+(Y-y)^{2}}
$$

$\mathrm{m}$

Where: $(\mathrm{X}, \mathrm{Y})$ is the object's true location, and $(\mathrm{x}, \mathrm{y})$ is the object's predicted location.

\section{Simulated Results:}

Many random locations of MS are used in simulation to obtain an accurate results, but just five locations are selected randomly and presented in this paper. The real points locations are shown in table (2):

These locations are located on the map and the simulation is run for each location to find the location using one of the three propagation models mentioned before. The rms error is calculated for each model using 3-BS's, 5-BS's and 7-BS's approaches. The results are given in Tables (3-5) :

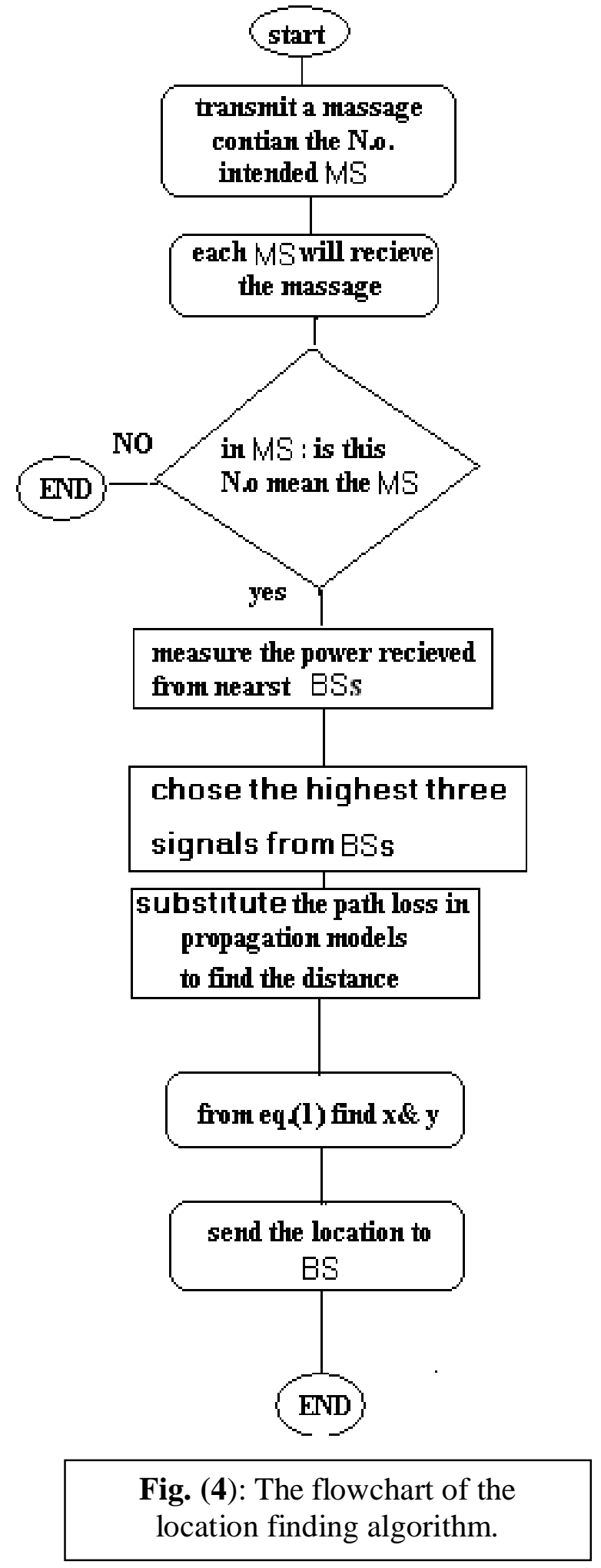

Table 2:Real location for mobile

\begin{tabular}{|c|c|c|c|c|c|}
\hline & Location1 & Location2 & Location3 & Location4 & Location5 \\
\hline x-pos & 2200 & 2600 & 2000 & 1500 & 3500 \\
\hline y-pos & 1500 & 500 & 1000 & 1000 & 2000 \\
\hline
\end{tabular}




$\begin{array}{lllll}\text { Al-Rafidain Engineering } & \text { Vol.19 } & \text { No.1 } & \text { February } & 2011\end{array}$

Table 3: rms error in UMTS model.

\begin{tabular}{|c|c|c|c|c|c|}
\hline approach & Location1 & Location2 & Location3 & Location4 & Location5 \\
\hline 3-BS's & 143.3 & 202.2 & 310 & N. A & 862 \\
\hline 5-BS's & 58 & 159 & 86 & 87.2 & 267 \\
\hline 7-BS's & 64 & 41 & 6.7 & 9.8 & 85.1 \\
\hline
\end{tabular}

N.A : Not Applicable

Table 4: $\mathrm{rms}_{\text {error }}$ in long-distance model.

\begin{tabular}{|c|c|c|c|c|c|}
\hline approach & Location1 & Location2 & Location3 & Location4 & Location5 \\
\hline 3-BS's & 445.38 & 470.48 & 551.8 & N. A & 1093 \\
\hline 5-BS's & 309.4 & 352.1 & 176 & 504.6 & 623 \\
\hline 7-BS's & 128.3 & 153.9 & 17.4 & 313.3 & 719 \\
\hline
\end{tabular}

Table 5: rms $_{\text {error }}$ in $\mathrm{OH}$ model.

\begin{tabular}{|c|c|c|c|c|c|}
\hline approach & Location1 & Location2 & Location3 & Location4 & Location5 \\
\hline 3-BS's & 460.7 & 482.9 & 563.17 & N. A & 1096 \\
\hline 5-BS's & 324.9 & 365.5 & 184.7 & 519.6 & 632 \\
\hline 7-BS's & 134.46 & 164 & 19.8 & 328 & 766 \\
\hline
\end{tabular}

As shown from the results given in tables above, one can see that the UMTS model has the minimum $\mathrm{rms}_{\text {error }}$ at each location for every approach (3-BS's, 5-BS's and 7-BS's) when compared with $\mathrm{OH}$ model and long-distance model.

Also it is seen that the $\mathrm{rms}_{\text {error }}$ is decreased when the number of base stations is increased, so the 7-BS's has the minimum $\mathrm{rms}_{\text {error }}$. At 7-BS's approach the $\mathrm{rms}_{\text {error }}$ is reduced to $(6.7 \mathrm{~m})$ in case of using UMTS model at location 3, and (17.4m) in case of using long-distance model while the $\mathrm{rms}_{\text {error }}$ is $(19.8 \mathrm{~m})$ when $\mathrm{OH}$ model is used.

Fig.(5) shows the effect of increasing the number of base stations in reducing the $\mathrm{rms}_{\text {error }}$ in UMTS model for five different locations.

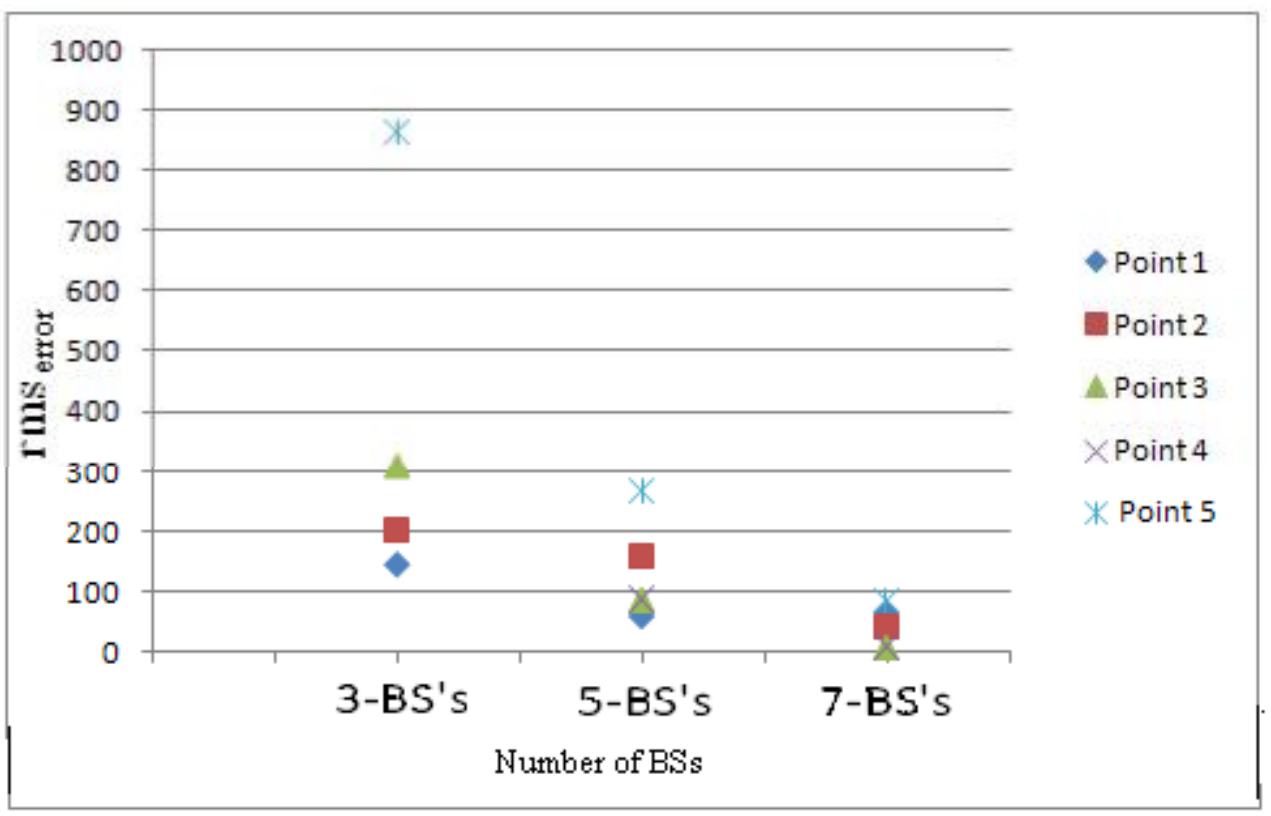

Fig. (5) The effect of increasing number of base stations on $\mathrm{rms}_{\text {error }}$ in UMTS model. 


\section{Conclusion}

In this paper, a new approach for object positioning and tracking systems is proposed and simulated. The approach based on RSSI in determining the position and tracking MS in the university of Mosul as a study case. Three propagation models are used in simulation and three approaches are applied (3-BS's , 5-BS's and 7-BS's). The $\mathrm{rms}_{\text {error }}$ is calculated for each model with different number of base stations at five random locations. The results showed that the UMTS model has the minimum $\mathrm{rms}_{\text {error }}$ when compared with other models. Also it is found that the $\mathrm{rms}_{\text {error }}$ can be reduced by increasing the number of base stations around the working area. Based on results obtained in this paper, it is recommended to use UMTS model in tracking and finding position algorithms because it has minimum rms error and it is recommended to increase the number of base stations (more than 5) around the working area to reduce the $\mathrm{rms}_{\mathrm{error}}$ and obtain an accurate results.

\section{References}

[1] Erol Hepsaydir " Mobile Positioning in CDMA Cellular Networks " Vehicular Technology Conference, 1999. VTC 1999 - Fall. IEEE VTS 50th. Volume 2 , 1999 Page(s):795 - 799 vol.2.

[2] M. Hallak, Dr. Mohamed S. Safadi, Dr.R. Kouatly " Mobile Positioning Technique using Signal Strength Measurement method with the aid of Passive Mobile Listener Grid", Information and Communication Technologies, 2006. ICTTA . $2^{\text {nd }}$, IEEE. Volume 1, PP:105 $-110$

[3]: H. Holma and A. Toskala "WCDMA for UMTS: Radio Access for Third Generation Mobile Communications", John Wiely \& Sons, Ltd, Third Edition, 2004.

[4] Farhad I. Mahmoud, Sami A. Mawjoud "Planning and design of a WCDMA network compatible with existing GSM system in Mosul city", $5^{\text {th }}$ International IEEE MultiConference on Systems, Signals and Devices, Jordan ,2008.

[5]: E.Hepsaydir "Analysis of Mobile Positioning Measurements in CDMA Network", Radio and Wireless Conference. RAWCON 99. IEEE , 1999 Page(s):73 - 76.

[6] ESTR TR 101112 Universal Mobile Telecommunications System (UMTS); Selection Procedures for the Choice of Radio Transmission Technologies of the UMTS (UMTS 30.03)

[7] Theodore S Rappaport "Wireless Communications principles and practice " John Wiley \& Sons. 2002. 